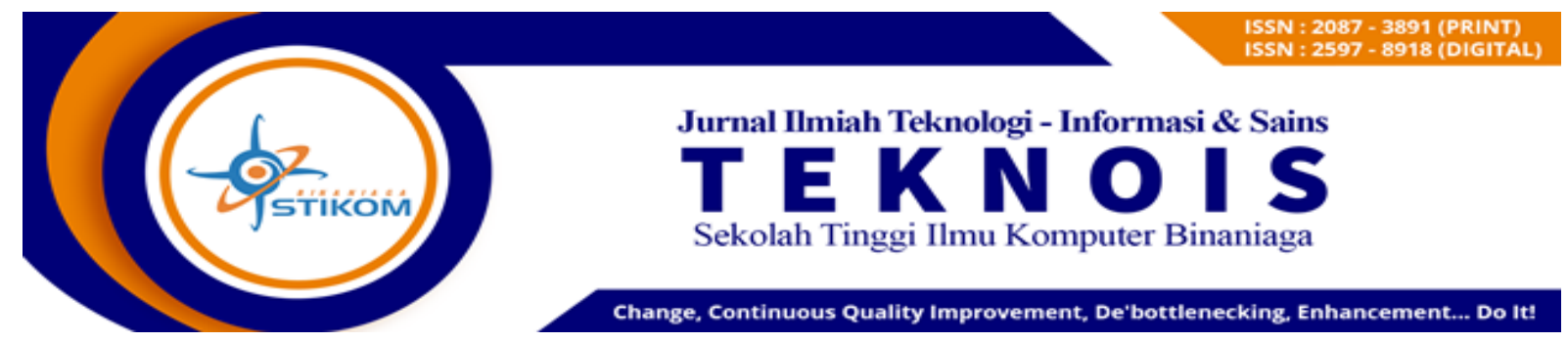

Article DOI : 10.36350/jbs.v11i2.114

Received: September; Accepted : October; Published : November

\title{
Implementasi dan Optimalisasi Voice Order Internet Protocol (VOIP) Menggunakan NDLC Untuk Komunikasi Antar Lantai
}

\author{
Ruhul Khomar $^{1 *}$, Arif Harbani ${ }^{2}$ \\ ${ }^{1}$ Sistem Informasi/Universitas Binaniga Indonesia \\ Email: - \\ ${ }^{2}$ Sistem Informasi/ Universitas Binaniga Indonesia \\ Email: arifharbani@stikombinaniaga.ac.id
}

\begin{abstract}
VoIP as an internet service is commonly called ip telephone. Internet infrastructure is needed in order to use or provide VoIP services. Some offices use local communication to communicate within the office environment itself, but cannot connect to other offices because it is only a local phone. This research aims to implement the Voice Over Internet Protocol (VoIP) by utilizing wireles local area network (WLAN) facilities by building a VoIP server. The development model used in this research is a user interface that is built alone to be applied on Android phones. This user interface is as a face-to-face tool for fellow VoIP users. The study was conducted at the West Bogor sub-district office with 23 respondents as a sample of application trial subjects. The results of the analysis showed $78.66 \%$ of the application eligibility level, showing the application or system made was considered good.
\end{abstract}

Keywords: Wireles Local Area Network (WLAN); Voice Over Internet Protokol (VoIP); User Interface.

\section{ABSTRAK}

VoIP sebagai layanan internet biasa disebut IP telepon. Infrastruktur internet dibutuhkan agar dapat menggunakan atau menyediakan layanan VoIP. Beberapa kantor ada yang menggunakan komunikasi lokal untuk berkomunikasi didalam lingkungan kantor itu sendiri, akan tetapi tidak bisa terhubung ke kantor lain karena hanya bersifat telepon lokal. Penelitian ini bertujuan untuk mengimplementasikan Voice over Internet Protokol (VoIP) dengan memanfaatkan fasilitas Wireles Local Area Network (WLAN) dengan membangun sebuah server VoIP. Model pengembangan yang digunakan dalam penelitian ini adalah User Interface yang dibangun sendiri untuk di aplikasikan pada handphone Android. User Interface ini adalah sebagai sarana tatap muka bagi sesama pengguna VoIP. Penelitian ini dilakukan di kantor kecamatan Bogor Barat dengan 23 responden sebagai sampel subjek uji coba aplikasi. Hasil analisa menunjukan 78,66\% dari tingkat kelayakan aplikasi, menunjukan aplikasi atau sistem yang dibuat dinilai sudah baik dan pengguna sudah merasa puas.

Keywords: Wireles Local Area Network (WLAN); Voice Over Internet Protokol (VoIP); User Interface.

\section{A. PENDAHULUAN}

\section{Latar Belakang}


VoIP atau Voice over Internet Protocol adalah teknologi yang mampu melewatkan trafik suara, video dan data yang berbentuk paket melalui jaringan IP. Jaringan IP sendiri merupakan jaringan komunikasi data yang berbasis Packed-Switch, sehingga bisa menelepon dengan menggunakan jaringan IP atau internet. VoIP memungkinkan perutean, access server dan multiservice access concentrator membawa dan mengirim suara dan fax melintasi jaringan IP. Banyak keuntungan yang dapat diambil diantaranya adalah dari segi biaya jelas lebih murah dari tarif telepon tradisional.

Beberapa kantor kecamatan ada yang menggunakan komunikasi lokal untuk berkomunikasi didalam lingkungan kantor kecamatan itu sendiri akan tetapi tidak bisa terhubung ke kantor lain karena hanya bersifat telepon lokal. Disamping itu juga sering terjadi gangguan pada jaringan telepon yang ada pada kantor kecamatan terkait seperti jaringan komunikasi handphone dan telepon.

Dalam penelitian ini yang dilakukan yaitu mengimplementasikan Voice Over Internet Protokol (VoIP) dengan memanfaatkan fasilitas Wireles Local Area Network (WLAN) dengan membangun sebuah server VoIP menggunakan Linux Debian dan User Interface yang dibangun sendiri untuk di aplikasikan pada handphone Android. User Interface ini adalah sebagai sarana tatap muka bagi sesama pengguna VoIP.

User Interface yang dibangun merupakan salah satu aplikasi yang dapat diterapkan pada handphone dengan sistem operasi Android dan aplikasi ini dibangun agar sesama pengguna VoIP dapat saling berkomunikasi dengan mudah.

\section{Permasalahan}

Berdasarkan hal tersebut maka identifikasi masalah dalam penelitian ini adalah :

a. Belum mampu menghemat biaya.

b. Belum efektifnya komunikasi di kantor kecamatan.

\section{Tujuan}

Adapun tujuan dari penelitian ini adalah :

a. Menerapkan Voice Over Internet Protocol (VoIP) untuk komunikasi Softphone di kecamatan Bogor Barat

b. Mengukur tingkat keoptimalan komunikasi dengan menggunaan Voice Over Internet Protocol (VoIP)

c. Meningkatkan kualitas suara yang dihasilkan

d. Mampu merancang jaringan komunikasi secara jelas

e. Mengembangkan Voice Over Internet Protocol untuk mengoptimalkan komunikasi

\section{B. METODE}

Metode yang digunakan adalah metode penelitian pengembangan, artinya bahwa penelitian yang dilakukan untuk melakukan uji coba terhadap permasalahan tertentu dengan penggunaan teori tertentu, didapatkan hasil yang tepat antara permasalahan dengan teori yang digunakan.

\section{Prosedur Pengembangan}

Prosedur pengembangan merupakan langkah-langkah dari proses pengembangan yang dilakukan dapat dijelaskan sebagai berikut:

a. Penelitian dan Pengumpulan Data : Studi literatur digunakan untuk menemukan konsep atau landasan teoritis yang memperkuat suatu produk dan studi lapangan sebagai pengukuran kebutuhan dan penelitian dalam skala kecil.

b. Perencanaan mencakup : a) tujuan dari penggunaan produk; b) siapa pengguna dari produk tersebut; c) deskripsi dari komponen-komponen produk dan penggunaannya.

c. Pengembangan Produk Awal dikembangkan oleh peneliti bekerja sama atau meminta bantuan para ahli dan atau praktisi yang sesuai dengan bidang. Pada tahap ini sering juga disebut dengan tahap validasi ahli.

d. Uji coba produk awal / Uji Coba Terbatas mencakup peneliti mengadakan pengamatan secara intensif dan mencatat hal-hal penting yang dilakukan oleh responden. 
Volume 11 Number 2 November 2021 Page. 51-60

Journal Homepage : http://teknois.stikombinaniaga.ac.id/index.php/JBS

DOI Link : http://doi.org/10.36350/jbs.v11i2

e. Penyempurnaan Produk Awal lebih banyak dilakukan dengan pendekatan kualitatif. Evaluasi yang dilakukan lebih terhadap proses, sehingga perbaikan yang dilakukan bersifat perbaikan internal.

f. Uji Coba Lapangan Lebih Luas masih difokuskan kepada pengembangan dan penyempurnaan materi produk.

g. Penyempurnaan Produk Hasil Uji Lapangan Lebih Luas didasarkan pada evaluasi hasil sehingga pendekatan yang digunakan adalah pendekatan kuantitatif.

h. Uji Coba Produk Akhir dilaksanakan dalam bentuk desain eksperimen. Desain pertama merupakan desain eksperimen murni, karena kedua kelompok eksperimen dirandom atau disamakan.

i. Revisi atau Penyempurnaan Produk Akhir sudah didapatkan suatu produk yang tingkat efektivitasnya dapat dipertanggungjawabkan.

j. Diseminasi dan Implementasi yang dikembangkan akan membutuhkan sosialisasi yang cukup panjang dan lama. Biasanya proses desiminasi dan implementasi akan berhadapan dengan berbagai masalah kebijakan, legalitas, pendanaan, dan lain-lain.

\section{Uji Coba Produk}

a. Desain Uji Coba adalah pengujian kepada ahli jaringan komputer dengan menggunakan kuesioner

b. Subyek Uji Coba adalah dengan menggunakan kuesioner kelayakan pengguna, kuesioner diisi oleh pengguna jaringan komputer.

\section{Jenis Data}

a. Jenis Data Ahli adalah data yang berhubungan dengan teknis pengembangan suatu alat dan aplikasi yang dapat dinilai dari segi usability, fungtionality, dan komunikasi visual.

b. Jenis Data Pengguna adalah berupa kualitas produk ditinjau dari kesesuaian, keakuratan, kecepatan sistem dalam penggunannnya dan fungsi-fungsi sistem secara keseluruhan.

\section{Instrumen Pengumpulan Data}

Dalam pengumpulan data yang akan digunakan dalam penampilan ini yaitu :

a. Observasi dilakukan dengan meninjau secara langsung kondisi yang sudah ada dan berjalan di lapangan.

b. Kuesioner merupakan proses pengumpulan data yang dilakukan dengan cara memberikan seperangkat pertanyaan tertulis kepada responden untuk dijawabnya.

c. Studi Pustaka dilakukan kegiatan seperti membaca, meneliti dan menganalisis buku-buku, majalah dan artikel yang berkaitan dengan masalah VoIP

Teknik pengolahan menggunakan pengukuran skala likert. Tingkat persetujuan yang dimaksud dalam skala Likert ini terdiri dari 5 pilihan skala yang mempunyai gradasi dari Sangat Setuju (SS) hingga Sangat Tidak Setuju (STS).

a. Kuesioner Untuk Ahli Sistem Informasi

Tabel 1. Kuesioner Ahli VoIP

\begin{tabular}{|l|l|l|l|l|}
\hline \multirow{2}{*}{ No. } & \multirow{2}{*}{ Aktivitas } & \multirow{2}{*}{ Hasil Yang Diharapkan } & \multicolumn{2}{|l|}{ Taraf Ketercapaian } \\
\cline { 3 - 5 } & & Tampilan halaman depan pada aplikasi VoIP & Tidak \\
\hline 1 & User Interface & Taman & & \\
\hline 3 & Interaksi System & Tampil Halaman Laporan Pembayaran & & \\
\hline 4 & Prosedur Program & User dapat menggunakan aplikasi VoIP dengan mudah & & \\
\hline 5 & Waktu Respon & $\begin{array}{l}\text { Membutuhkan waktu yang cepat dalam proses } \\
\text { Komunikasi menggunakan VoIP }\end{array}$ & & \\
\hline
\end{tabular}

\section{b. Kuesioner Untuk Pengguna}

Tabel 2. Kuesioner Pengguna

\begin{tabular}{|l|l|l|c|c|c|c|}
\hline \multirow{2}{*}{ No. } & \multirow{2}{*}{ Pernyataan } & SS & S & CS & TS & STS \\
\hline Kualitas VoIP & & & & & \\
\hline 1 & Kualitas Suara VoIP Jernih? & & & & & \\
\hline 2 & VoIP Memberikan kenyamanan saat melakukan komunikasi ? & & & & & \\
\hline
\end{tabular}


Volume 11 Number 2 November 2021 Page. 51-60

Journal Homepage : http://teknois.stikombinaniaga.ac.id/index.php/JBS

DOI Link : http://doi.org/10.36350/jbs.v11i2

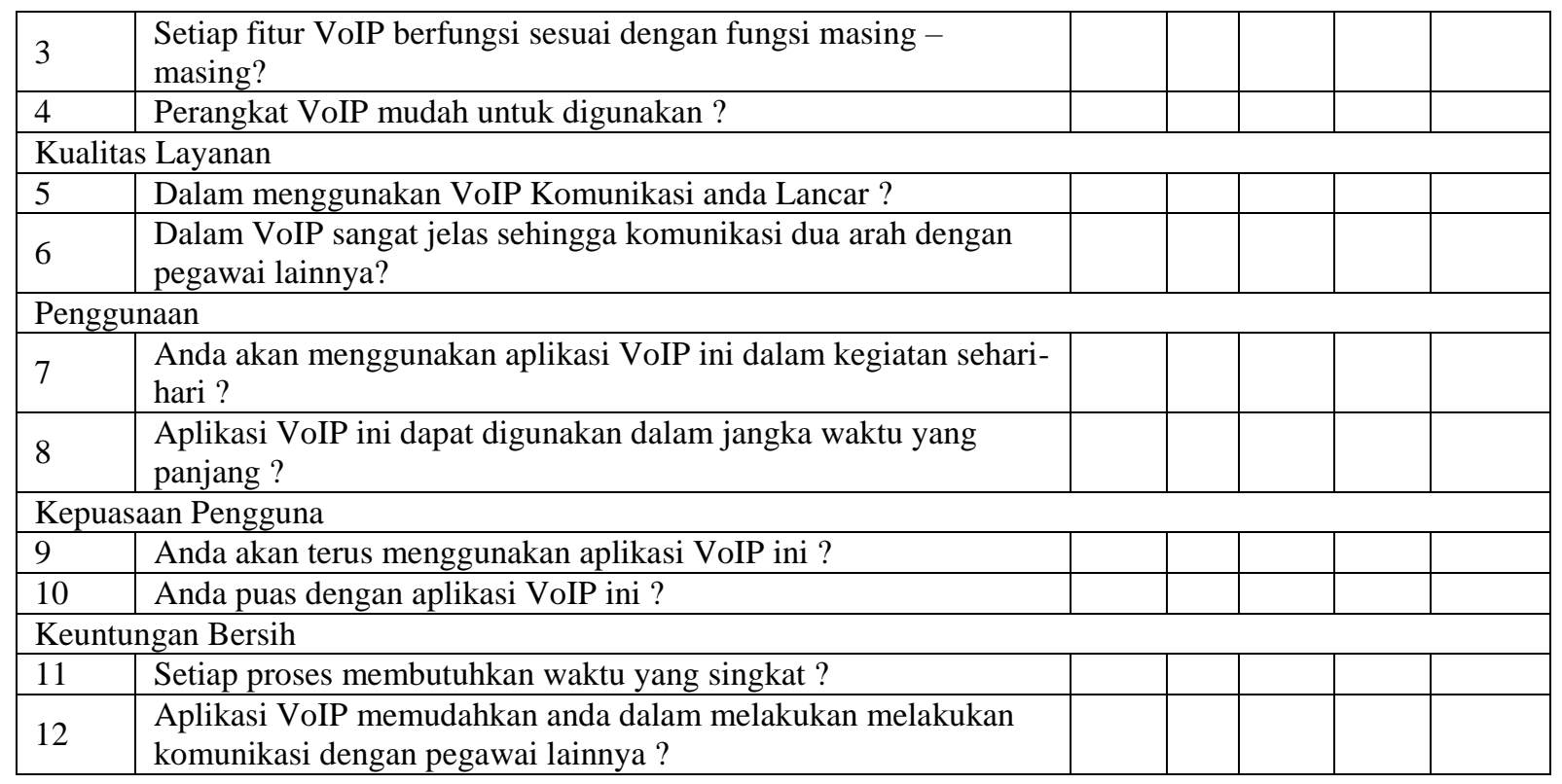

\section{Teknik Analisa Data}

Data hasil penilaian kelayakan dianalisis dengan teknik analisis deskriptif, sebagai berikut:

$$
\text { Presentase }=\frac{\sum \text { (jawaban } \times \text { bobot tiap pilihan) }}{n \times \text { bobot tertinggi }} \times 100 \%
$$

Keterangan : $\sum=$ Jumlah; $\mathrm{n}=$ Jumlah seluruh item

Tabel 3. Konversi Tingkat Pencapaian

\begin{tabular}{|c|c|}
\hline Tingkat Ketercapaian & Kualifikasi \\
\hline $90 \%-100 \%$ & Sangat Layak \\
\hline $75 \%-89 \%$ & Layak \\
\hline $65 \%-74 \%$ & Cukup Layak \\
\hline $55 \%-64 \%$ & Kurang Layak \\
\hline $0 \%-54 \%$ & Tidak Layak \\
\hline
\end{tabular}

\section{HASIL DAN PEMBAHASAN}

\section{Hasil}

\section{a. Pengumpulan Kebutuhan}

Merupakan kegiatan yang dilakukan untuk mengumpulkan kebutuhan-kebutuhan dalam pengembangan sistem dengan teknik pengumpulan data sebagai berikut :

1) Pengumpulan dokumen dilakukan untuk memenuhi kebutuhan dalam mengidentifikasi sebuah sistem, dokumen-dokumen tersebut berasal dari bagian Document Control.

2) Wawancara dilakukan dalam rangka mempelajari bagaimana proses informasi daily progress itu tersampaikan, wawancara dilakukan kepada Camat Bogor Barat Kota Bogor

\section{b. Analisis}

Analisis merupakan proses perencanaan, pembuatan dan penggambaran dari sistem yang akan dikembangkan. Dalam proses perancangan dibuatlah skenario yang dapat digunakan untuk mengidentifikasi kebutuhan sistem.

1) Alur sistem yang dikembangkan berupa pekerjaan terstruktur yang saling berhubungan untuk menyelesaikan suatu masalah tertentu atau yang menghasilkan suatu keluaran (produk/output) atau layanan (demi meraih tujuan tertentu) dan mendukung pencapaian tujuan serta sasaran strategis dari suatu organisasi. 
Volume 11 Number 2 November 2021 Page. 51-60 Journal Homepage : http://teknois.stikombinaniaga.ac.id/index.php/JBS

DOI Link : http://doi.org/10.36350/jbs.v11i2

2) Evaluasi Sistem dilakukan dengan cara menyebarkan kuesioner kepada pengguna dan melakukan pengujian validitas dan reliabilitas, untuk mengetahui apakah sistem dapat berjalan dengan baik dan layak untuk digunakan.

\section{c. Arsitektur VoIP}

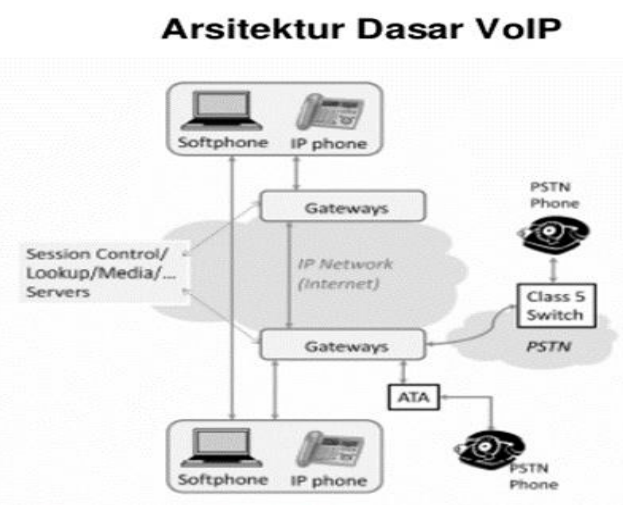

Gambar 1. Arsitektur Dasar VoIP

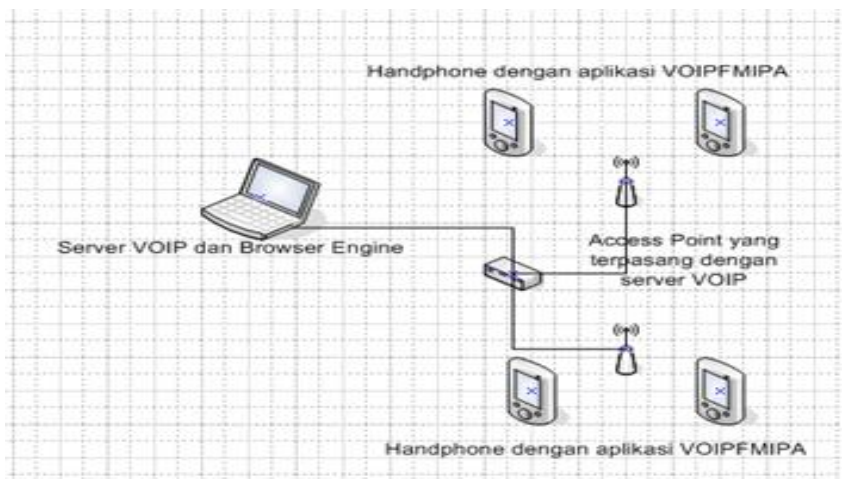

Gambar 2. Rancangan Topologi Jaringan VoIP

Di sisi jaringan paling luar terdapat komponen yang disebut "voice agent". Tugas dari komponen ini adalah untuk merubah informasi suara dari telepon menjadi bentuk data yang dapat ditransmisikan pada jaringan paket. Jaringan kemudian akan mentransmisikan data ke voice agent yang terhubung dengan telepon tujuan.

\section{d. Spesifikasi Server Lokal}

Spesifikasi hardware minimal server lokal yang harus disediakan untuk VOIP adalah sebagai berikut:

OS $\quad: 64$ bit dengan Windows 7 / Windows server 8 / Linux.

Processor $\quad$ : 4 core dengan frekuensi $1.6 \mathrm{GHz}$

RAM : minimal 8 GB

Networking : LAN card 2 buah.

Jenis $\quad$ : PC/Tower/Desktop dan bukan Laptop Port : 80 bisa di akses iis

Cadangan : Minimal 1 server (spek setara)

Spesifikasi hardware minimal Softphone pengguna yang harus disediakan untuk VOIP adalah sebagai berikut:

Jaringan $\quad$ : GSM, HSPA, LT; HSDPA: 42.2 Mbps \& HSUPA :5.76 Mbps, LTE Cat4; Dual SIM, Nano SIM

Hardware and : OS Android 6.0 (Marshmallow); Chipset : Qualcomm MSM8917 Snapdragon 425; CPU

Software Quad-core 1.4 GHz Cortex-A53; GPU : Adreno 306

Memori : RAM : 2 GB; Memori Internal 16 GB; Micro SD Up to 256 GB

Suara $\quad$ : Vibration; MP3, WAV ringtones, Loudspeaker, 3.5mm jack; Wi-Fi $802.11 \mathrm{~b} / \mathrm{g} / \mathrm{n}$

Konektivitas : $\quad$ A-GPS - A GPS, GLONASS, BDS; Hotspot, Bluetooth v4.2 A2DP, Radio FM, Micro USB V.2.0 
Volume 11 Number 2 November 2021 Page. 51-60

Journal Homepage : http://teknois.stikombinaniaga.ac.id/index.php/JBS

DOI Link : http://doi.org/10.36350/jbs.v11i2

Sensor : : Accelerometer, Proximity, Compass

Baterai : Baterai Li-Ion $2500 \mathrm{mAh}$, Non-Removable

\section{e. Cara Kerja VoIP}

Prinsip kerja VoIP adalah mengubah suara analog yang didapatkan dari speaker pada komputer menjadi paket data digital, kemudian dari PC diteruskan melalui Hub/ Router/ ADSL Modem dikirimkan melalui jaringan internet dan akan diterima oleh tempat tujuan melalui media yang sama. Pada perkembangannya, sistem koneksi VoIP mengalami evolusi seperti pesawat telepon biasa terhubung dengan jaringan VoIP. Jaringan data digital dengan gateway untuk VoIP memungkinkan berhubungan dengan PABX atau jaringan analog telepon biasa. Bentuk komunikasi bukan hanya suara saja. Bisa berbentuk tulisan (chating) atau jika jaringannya cukup besar bisa dipakai untuk Video Conference. Dalam bentuk yang lebih lanjut komunikasi ini lebih dikenal dengan IP Telephony yang merupakan komunikasi bentuk multimedia sebagai kelanjutan bentuk komunkasi suara (VoIP).

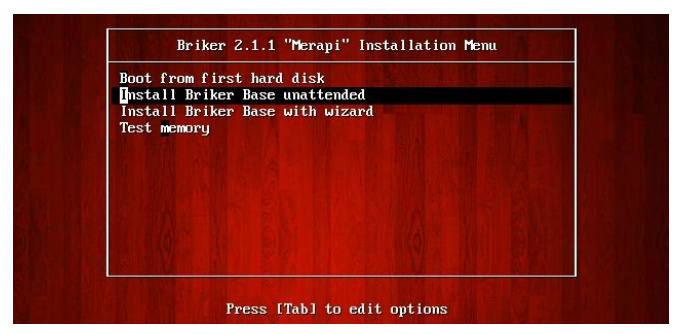

Gambar 3. Tampilan Awal

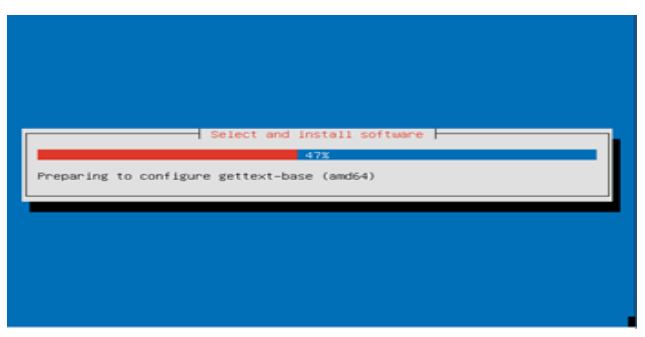

Gambar 4. Tampilan Instalasi

Pada gambar 3. tersedia Pilihan (Base Unattended) untuk instalasi yang cepat, pilihan ke 2 yaitu Base With Wizzard.

Pada gambar 4. ditampilkan proses instalasi

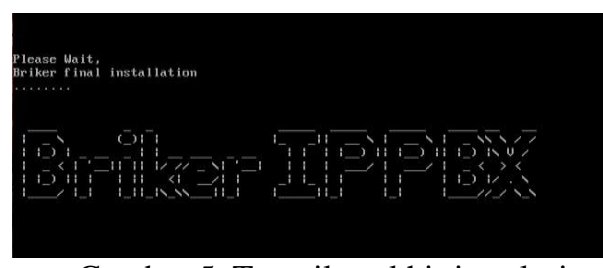

Gambar 5. Tampilan akhir instalasi

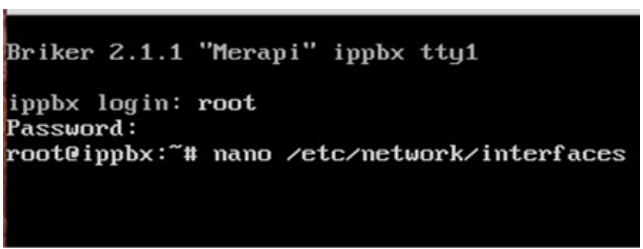

Gambar 6. Layar tampilan boot

Gambar 5 Setelah selesai vm akan terestart dan didapati tampilan login shell yang menandakan Briker sudah berhasil diinstall

Pada gambar 6. Login sebagai root dengan memasukkan nama user dan password yang telah dikonfigurasi pada proses instalasi

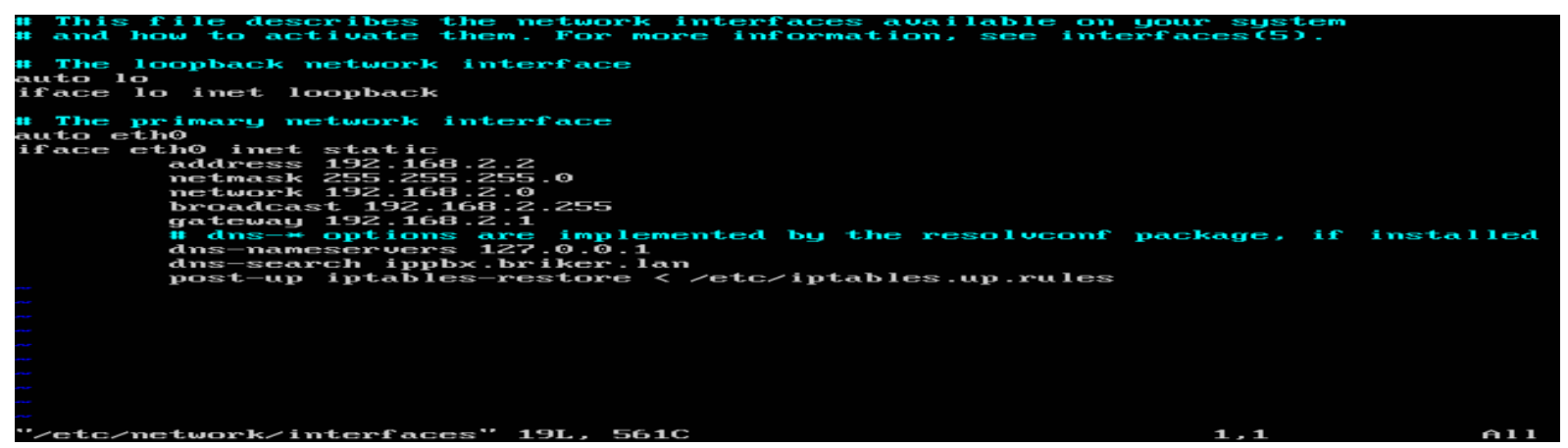

Gambar 7. Tampilan untuk mengganti IP address Briker 
Volume 11 Number 2 November 2021 Page. 51-60 Journal Homepage : http://teknois.stikombinaniaga.ac.id/index.php/JBS

DOI Link : http://doi.org/10.36350/jbs.v11i2

Konsol edit entri file diperlihatkan pada gambar 7. diatas.

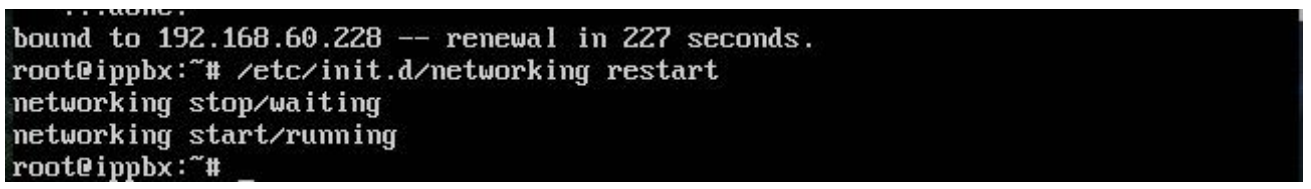

Gambar 8. Restart network

Restart layanan networking dengan perintah: /etc/init.d/netwoking restart pada gambar 8.

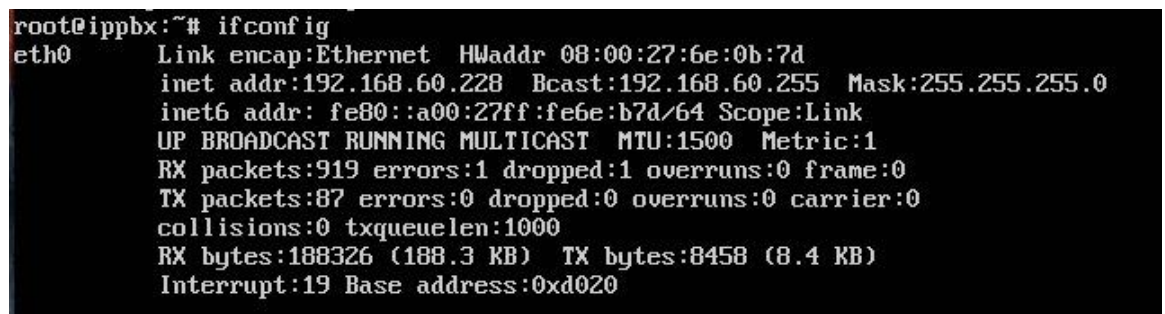

Gambar 9. Cek konfigurasi IP address

Pengujian konfigurasi IP address sudah berhasil diterapkan pada server Briker dengan perintah: ifconfig diperlihatkan pada gambar 9.

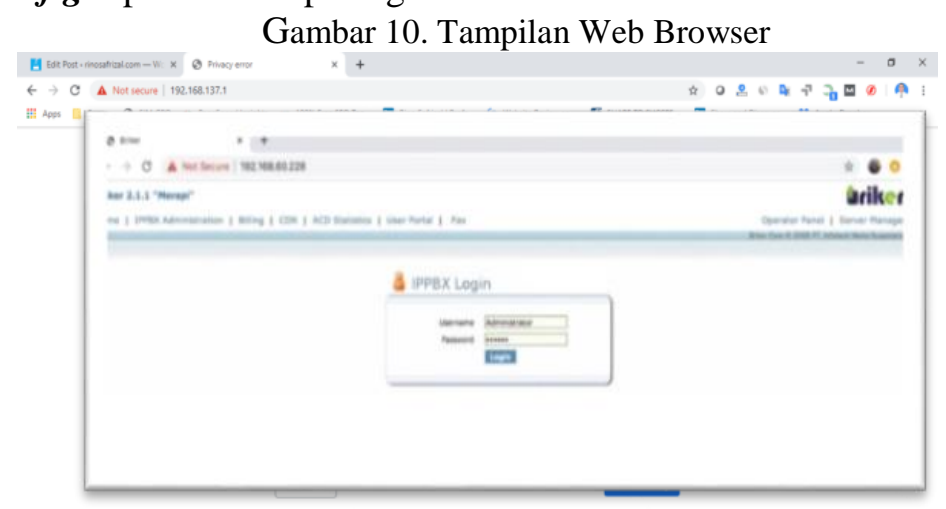

Gambar 11. Tampilan Login

Halaman seperti di atas menunjukan Unsafe pada gambar 10. dan selanjutnya akan diarahkan ke halaman login Briker.

Halaman utama Briker, login dengan username "administrator" dan password "Briker" pada gambar 11 . 
Volume 11 Number 2 November 2021 Page. 51-60 Journal Homepage : $\underline{\text { http://teknois.stikombinaniaga.ac.id/index.php/JBS }}$ DOI Link : http://doi.org/10.36350/jbs.v11i2

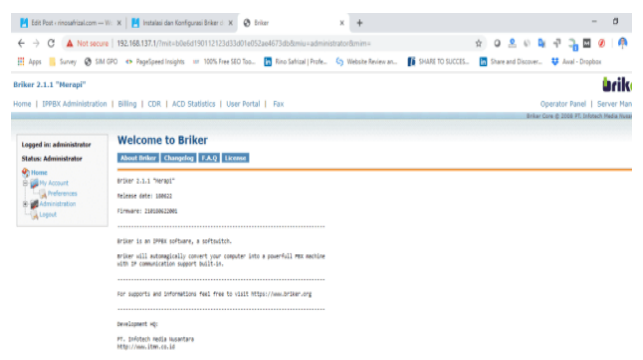

Gambar 12. Halaman Extension

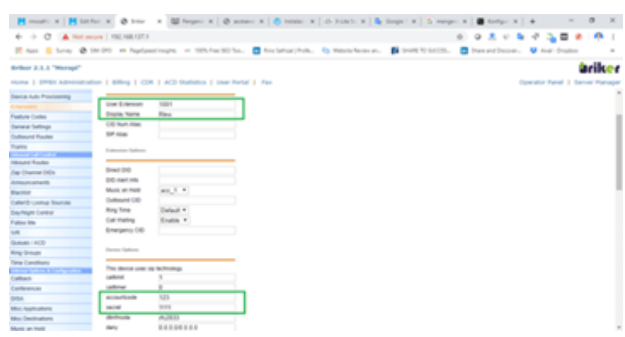

Gambar 13. Detail Halaman Extension

Halaman extension ditunjukan pada gambar 12. berfungsi untuk entri user extension display name, account code, dan secret pada form add extension :

User extension: 1001

Account code: 123
Display name: Rino

Secret: 1111

Keterangan gambar 13 :

User Extensions : Nomor extension, misal 1001. Biasanya berupa angka (numeric)

Display Name : Nama yang akan digunakan sebagai Caller ID ketika melakukan panggilan

Secret

: Password yang digunakan user untuk proses otentikasi saat registrasi extension pada User Agent

Account Code : Digunakan pada pengaturan billing

Perubahan konfigurasi pada gambar 14.

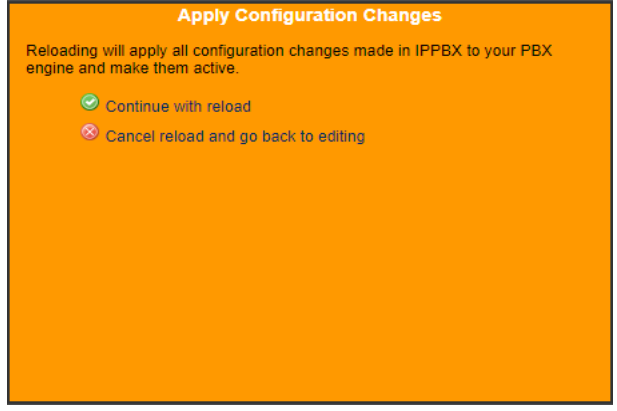

Gambar 14. Tampilan Apply Configuration Change

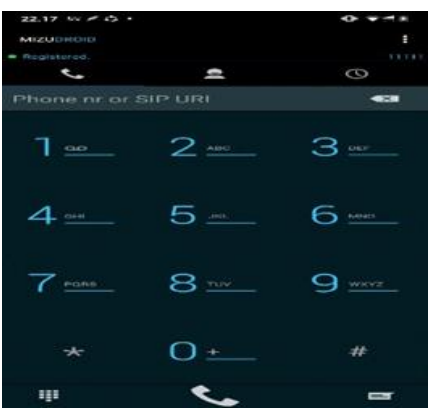

Gambar 15. Tampilan Setting Telepon

Seting Server, Username dan Password Account VoIP , diperlihatkan pada gambar 16.

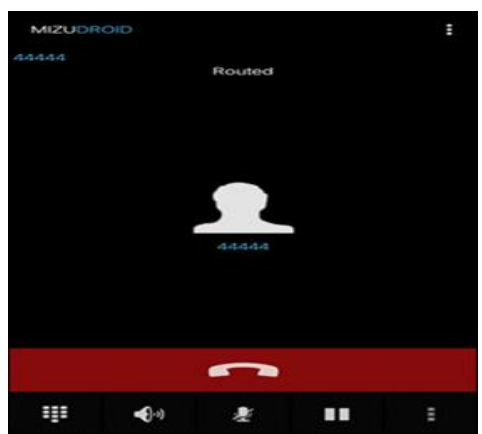

Gambar 16. Tampilan papan tombol

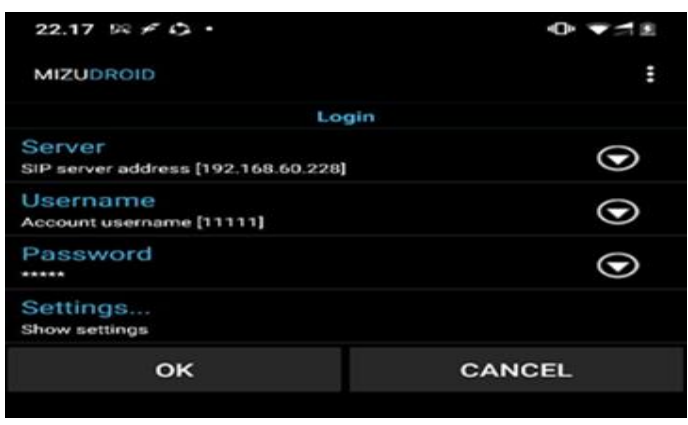

Gambar 17. Tampilan Panggilan Keluar Entri nomor yang sebelumnya sudah terdaftar pada gambar 17 .

\section{Pembahasan}

a. Analisa Data 
Volume 11 Number 2 November 2021 Page. 51-60

Journal Homepage : http://teknois.stikombinaniaga.ac.id/index.php/JBS

DOI Link : http://doi.org/10.36350/jbs.v11i2

Data yang diperoleh melalui instrumen penelitian ini diuji dengan menggunakan statistik dekriptif kuantitatif dimaksudkan untuk menggambarkan karakteristik data pada masingmasing variabel. Hasil presentase digunakan sebagai jawaban atas kelayakan dari aspekaspek yang diteliti dengan hasil angket dijumlahkan berdasarkan point jawaban lalu dibandingkan dengan jumlah yang diharapkan untuk memperoleh presentase berikut hasil kelayakan presentase dalam penelitian ini.

Tabel 4. Presentase kelayakan

\begin{tabular}{|l|r|r|r|}
\hline Aspek penilaian & Skor observasi & Skor yang diharapkan & Kelayakan \\
\hline Kualitas VOIP & 499 & 600 & $83.16 \%$ \\
\hline Kualitas layanan & 227 & 300 & $75,66 \%$ \\
\hline Penggunaan & 225 & 300 & $75 \%$ \\
\hline Kepuasaan Pengguna & 234 & 300 & $78 \%$ \\
\hline Keuntungan Bersih & 231 & 300 & $77 \%$ \\
\hline Total & 1.416 & 1.800 & $78,66 \%$ \\
\hline
\end{tabular}

Persentase yang didapat sebesar 78,66\%, maka dapat dikategorikan “layak".

\section{b. Evaluasi Sistem}

Aplikasi atau sistem yang dibuat ini dinilai sudah baik dan pengguna sudah merasa puas dan menerapkan sistem yang sudah dibuat ini. Penilaian dilihat dari hasil penyebaran kuesioner.

\section{c. Penggunaan Sistem}

Dikarenakan pengguna sudah merasa puas terhadap aplikasi yang dibuat maka aplikasi ini sudah bisa digunakan di gedung kecamatan.

\section{KESIMPULAN DAN SARAN}

1. Kesimpulan

Berdasarkan hasil penelitian dapat ditarik kesimpulan :

a. Jaringan Voice Over Internet Protocol (VoIP) berbasis Wireless Local Area Network (WLAN) berhasil dibuat dan di implementasikan Kantor Kecamatan Bogor Barat, dengan menggunakan Linux Briker 2.1.1 sebagai server VoIP, Handphone Android dari seluruh karyawan sebagai pengguna VoIP, dan aplikasi VoIP sebagai User Interface bagi pengguna.

b. Aplikasi VoIP yang dibuat dan pengguna sudah merasa puas mendapatkan presentasi kelayakan 78,66 \% maka aplikasi ini dikatakan layak sudah bisa digunakan di gedung kecamatan.

2. Saran

Diharapkan pada pengembangan dan perbaikan selanjutnya yaitu:

a. Menambahkan jaringan yang lebih luas seperti Internet dengan aplikasi yang melibatkan seluruh sistem operasi agar menghasilkan sistem jaringan yang lebih baik.

b. Penambahan perangkat video supaya bisa berinteraksi tatap muka.

c. Integrasi infrastruktur Jardiknas dengan sistem VoIP yang dirancang menghasilkan indikator-indikator keberhasilan dalam setiap melakukan konfigurasi awal hingga dapat dilakukannya komunikasi tatap muka (video conference).

\section{E. DAFTAR PUSTAKA}

[1] Arikunto, Suharsimi. (2002), Prosedur Penelitian, Jakarta: Rineka Cipta.

[2] Hafian, Fany, (2005), Mudah dan Murah Membangun Jaringan Internet dengan Linux Router Project Leaf Bearing.Jakarta : Elex Media Komputindo,

[3] Prakoso, (2005), Jaringan Komputer Linux: Konsep Dasar, Instalasi, Aplikasi, Keamanan dan Penerapan. Yogyakarta : Andi.

[4] Iskandarsyah, M.(2003), Cara Mudah Membangun Jaringan VoIP . Bandung: Kawan Pustaka.

[5] Sopandi, Dede. (2008), Intalasi dan Konfigurasi Jaringan Komputer. Bandung: Informatika 
Volume 11 Number 2 November 2021 Page. 51-60

Journal Homepage : http://teknois.stikombinaniaga.ac.id/index.php/JBS

DOI Link : http://doi.org/10.36350/jbs.v11i2

[6] Safaat. (2010). Android : Pemrograman Aplikasi Mobile Smartphone dan Tablet PC. Bandung: Informatika

[7] Sudjana. (2005). Metode Statistika. Bandung: Tarsito

[8] Sugeng, Winarno. (2008). Membangun Telepon Berbasis VOIP. Bandung : Informatika Bandung.

[9] Sugiyono. (2015). Metode Penelitian Kuantitatif, Kualitatif dan R\&D. Bandung: Alfabeta.

[10] Yani, Ahmad. (2007), Panduan Membangun Jaringan Komputer.Bandung : Kawan Pustaka. 